\title{
Süper Ligde Mücadele Eden Bir Kulübün U16 Ligi Futbolcularının Kuvvet, Sürat ve Dikey Sıçrama Performansları Arasındaki İlişkinin İncelenmesi
}

\author{
Sinan SEYHAN* \\ Celal Bayar Üniversitesi, Spor Bilimleri Fakültesi, MANISA
}

DOI: 10.31680/gaunjss.521035

Orijinal Makale / Original Article

Geliş Tarihi / Received: 01.02.2019 Kabul Tarihi / Accepted: 03.03.2019 Yayın Tarihi / Published: 22.03.2019

\begin{abstract}
Öz
Bu çalışmanın amacı Türkiye Futbol Federasyonu Spor Toto Süper Liginde mücadele eden profesyonel bir takımının alt yapısında (U16 liginde) mücadele eden futbolcuların $5 \mathrm{~m}, 10 \mathrm{~m}$ ve $30 \mathrm{~m}$ sürat performansları ile dikey sıçrama performansları ve kuvvet değerleri arasındaki ilişkiyi belirlemektir. Katılımcıların yaşları, boy uzunlukları, ağırlıkları, belirlenen 1RM (1 tekrar maksimum kuvvet) ile kuvvet performansları, $5 \mathrm{~m}, 10 \mathrm{~m}, 30 \mathrm{~m}$ sürat performans verileri, sıçrama performansları counter movement jump (CMJ) ve squat jump(SJ) ile belirlendi. Çalışmaya katılan toplam 23 futbolcunun tanımlayıcı özellikleri olarak yaş ortalaması: 15,78, \pm 42 yıl, boy uzunluğu: $172,43 \pm 7,89 \mathrm{~cm}$, vücut kütlesi: $62,04 \pm 7,61 \mathrm{~kg}$ olarak tespit edildi. Çalışmadan elde edilen bulgular doğrultusunda $0-5 \mathrm{~m}$ koşu performansı ile back squat 1RM performansı $(p=0,57)$ arasında anlamlı bir ilişki olduğu görüldü $(p<0.001)$. Diğer bir yandan süratin diğer kompanentleri olan maksimum hıza ulaşma-yavaşlama $(10 \mathrm{~m}, 30 \mathrm{~m})$ ile sıçrama performanslarının kuvvet performansları ile anlamlı bir ilişki göstermediği tespit edildi. Sonuç olarak, antrenörlerin başarılı bir performans için sporculara dikey güç üretimini artıracak squat, deadlift gibi büyük kas gruplarına yönelik antrenmanları uygulanması, futbolcularının oyun sırasında kaslarının çok kısa sürede ve etkili şekilde kasılması ile çok daha başarılı başlangıç koşuları yapmalarına imkân sağlayabilir.
\end{abstract}

Anahtar Sözcükler: Futbol, Kuvvet, Sürat

\section{The Relationship Between Strength, Sprint and Vertical Jumping Performances of U16 League Soccer Players in a Super League}

\begin{abstract}
The aim of this study in the infrastructure of a professional team, which competes in the Turkey Spor Toto Super League, which competes in the (U16 league) soccer player $5 \mathrm{~m}, 10 \mathrm{~m}$ and $30 \mathrm{~m}$ sprint to determine the relationship between performance and strength performance with vertical jump values. The ages, lengths, weights of the participants, strength performances with 1RM (1 repetition maximum force), $5 \mathrm{~m}, 10 \mathrm{~m}, 30 \mathrm{~m}$ speed performance data and jump performance were determined by countermovement jump (CMJ) and squat jump (SJ). The mean age of the participants was $15.78 \pm .42$ years, $172.43 \pm 7.89 \mathrm{~cm}$ and body mass was $62.04 \pm 7.61 \mathrm{~kg}$. According to the findings obtained from the study, a significant relationship was found between $0-5 \mathrm{~m}$ running performance and back squat 1RM performance $(p=0,57)(p<0.001)$. On the other hand, the other components of the speed, the maximum speed to reach-deceleration $(10 \mathrm{~m}, 30 \mathrm{~m})$ and jump performances did not show a significant relationship with strength performance. As a result, the practice of trainers for large muscles such as squats and deadlifts, which will increase the vertical power production of the athletes for successful performance, can enable the players to perform much more successful start-ups during the game in a very short time and effectively contract their muscles.
\end{abstract}

Key Words: Soccer, Strength, Sprint

\footnotetext{
* Sorumlu Yazar: Sinan SEYHAN
}

E-mail: sinanseyhan@gmail.com 


\section{Giriş}

Yıllardır futbol oyunun daha iyi nasıl oynanacağı, daha yüksek performansa nasıl ulaşılacağı ile ilgili çok sayıda araştırma yapılmıştır. Bu araştırmalar içerisinde fiziksel performans, teknik-taktik analizler, psikolojik, sosyolojik ve ekonomik değerlendirmeler yapılmaktadır. Oyuncuların yüksek performans düzeylerine ulaşabilmesi için yapılmış olan çalışmalarda futbolcuların başarılı olabilmelerinin; yetenek, dayanıkılık, kuvvet, sürat, esneklik, koordinasyon, antropometrik faktörler, hareketlilik, motivasyon ve teknik-taktik yeterliliklerin eğitimine ve gelişimine bağlı olduğu görülmektedir (Akt., 2010; Turna ve Kılınç, 2018).

Tüm spor branşlarında olduğu gibi sürat, futbolda da iyi bir performansın göstergesi olarak bilinir. Futbol oyununda ortalama sürat süresi 2 ile 4 sn arasında değişmekle birlikte, futbolcuların sürat ile yer değiştirmeleri büyük çoğunlukla 20 metreden kısa olmaktadır (Vigne ve ark., 2010). Futbol ile ilgili sürat becerileri, herhangi bir sapma olmadan düz sürat koşuları, çeviklik ve kısa aralıklı sürat koşuları olarak sınıflandırılabilir. Sürat koşuları ivmelenme, maksimum hıza ulaşma ve yavaşlama gibi fazları olan temel motorik performans belirleyicidir (Mero ve ark., 1992). Sürat performansı bir futbol maçında futbolcuların toplam koşu mesafelerinin yaklaşık olarak \% 1-11'ini oluşturur. Bu oran 90 dakikalık bir futbol müsabakasında topun oyunda olduğu zamanın \% 0,5-3'üne karşılık gelmektedir (Bangsbo ve ark., 1991).

Profesyonel futbolcuların müsabaka süresince karşı takımın ataklarına karşı topun kontrolünü sağlayabilmeleri, dengelerini koruyabilmeleri, süratli olabilmeleri kısaca iyi bir performans sergileyebilmeleri vücutlarının kısa sürede kasılmasıyla, kuvvetli ve güçlü bir vücut yapısı ile yakından ilişkilidir (Withers, 1982; Comfort ve ark., 2012; Wisloff ve ark., 2004). Literatürde futbolda kuvvet ve sürat performansı arasındaki ilişkiyi inceleyen birçok çalışma mevcuttur (Turna ve Kılınç, 2016). McBride ve ark., (2015) 17 futbolcu ile yapmış oldukları çalışmada, relative kuvvet (vücut ağırı̆̆ının 1 kg'ına karşılık gelen kuvvet miktarı) ile 36 metreye karşılık gelen 40 yard'ık sürat testi sonucunda elde edilen verilerin ilişkisi incelenerek, yüksek relative kuvvet ile sürat performansı arasında yüksek bir ilişki olduğunu göstermişlerdir (McBride ve ark., 2009).

Futbolda ani dönüş hareketleri, sürat ve yer değiştirme gibi futbol için kritik olan becerilerin, kasların ya da kas gruplarının kısa sürede güç üretebilmeleri ile 
birlikte kasılabilme hızlarında ki artış doğru orantıııır (Bangsbo ve ark., 1991). Kas temel kuvvet düzeylerinin dengeli ve güçlü olması optimal performansın ve sakatlıkların önlemesi açısından son derece önemli olduğu bilinmektedir. Büyük kas gruplarından olan hamstrings ve quadriceps kas grupları hızlanma, yavaşlama, sıçrama, havadan yere düşme ve diğer fiziksel aktivitelerde önemli rol oynamaktadır (Willigenburg ve ark., 2015). Bu kasların güçlü olması hem sürat hem de sıçrama performanslarının gelişmesine katkı sağlayacaktır.

Bu çalışma, Türkiye Futbol Federasyonu (TFF) Süper Ligi'nde mücadele eden profesyonel bir takımının alt yapısında (U16 liginde) mücadele eden futbolcuların $5 \mathrm{~m}$, $10 \mathrm{~m}$ ve $30 \mathrm{~m}$ sürat performansları, dikey sıçrama performansları ve kuvvet değerleri arasındaki ilişkiyi belirlemek için yapılmıştır.

\section{Yöntem}

$\mathrm{Bu}$ çalışmanın amacı TFF Spor Toto Süper Liginde mücadele eden profesyonel bir takımının alt yapısında (U16 liginde) mücadele eden futbolcuların $5 \mathrm{~m}$, $10 \mathrm{~m}$ ve $30 \mathrm{~m}$ sürat performansları, dikey sıçrama performansları ve kuvvet değerleri arasındaki ilişkiyi belirlemektir.

\section{Evren ve Örneklem}

Araştırmanın örneklem grubunu TFF Spor Toto Süper Lig Lefter Küçükandonyadis Sezonunda mücadele eden Akhisarspor Futbol Takımının U16 Ligi altyapı takımı $(n=23)$ futbolcuları oluşturmaktadır. Testler, sezon ortasında yapıldı ve bu süre zarfında, çalışmaya katılan tüm futbolcular takım antrenman programlarına ilaveten her hafta 2 kuvvet antrenmanı yaptılar. Tüm futbolcular testten bir önceki gün dinlendi. Testler öncesinde, normal antrenman öncesi yaptıkları gibi beslenme ve su tüketimine dikkat edecek şekilde teste katılmaları istendi.

\section{Veri Toplama Araçları}

Araştırmaya katılan futbolcuların boy ve vücut ağırlığı ölçümleri yapılmıştır.

Boy Uzunluğu: Futbolcuların boy uzunlukları hassaslık derecesi $0.01 \mathrm{~m}$ olan stadiometre (Seca, Almanya) ile anatomik duruşta, çıplak ayak, ayak topukları birleşik, denek nefesini tutmuşken, baş frontal düzlemde, baş üstü tablası verteks 
noktasına değer şekilde pozisyon alındıktan sonra ölçülmüş ve değerler ' cm' cinsinden kaydedilmiştir.

Vücut Ağırlığı: Futbolcuların vücut ağırlığı ölçümleri hassaslık derecesi $0.01 \mathrm{~m}$ olan stadiometre (Seca, Almanya) ile sporcuların üzerinde sadece şort varken, çıplak ayak ve anatomik duruş pozisyonunda ölçülmüş ve ' $k g$ ' cinsinden kaydedilmiştir.

Sürat: Tüm testlerden önce standartlaştırılmış aşamalı ısınma protokolü uygulandı. 10 dk'lık kısa aralıklarla sürat, dikey sıçrama, düşük seviye pliyometrik egzersizler, ayak hareketleri ve squat egzersizleri uygulandı. $30 \mathrm{~m}$ sürat testi elektronik fotosel sistemi ile $5 \mathrm{~m}, 10 \mathrm{~m}$ ve $30 \mathrm{~m}$ mesafelerden ölçümler alınarak yüksek çıkış tekniğine göre yaptırıldı. En yüksek değerleri alabilmek adına testi 3 defa tekrarlamaları istenmiş ve en iyi değer değerlendirmeye alınmıştır.

Countermovement Jumps (CMJ), Squat Jumps (SJ): CMJ ölçümü için, katıımcılardan normal dik duruş pozisyonunda kollar yanda ve kolların da yardımıyla dizlerden aşağıya doğru hızlı bir çökme hareketi yaptıktan sonra maksimum kuvvet ile yukarı sıçramaları istendi. SJ ölçümü ise, katılımcılarından dizleri kırık, çömelme pozisyonunda (Squat), eller belde olacak şekilde maksimum kuvvet ile yukarı sıçramaları istendi. Her katılımcı Iphone 7 (Apple Inc USA) telefonu kullanılarak geçerliliği kanıtlanmış My Jump 2 uygulamasında bulunan yüksek hızlı kamera ile dikey sıçrayışları kaydedildi (Balsalobre-Fernandez ve ark., 2015). Her katıımcının mümkün olabildiğince yükseğe 3 defa dikey sıçraması istendi. Her atlama sonunda 2 dakikalık bir pasif dinlenme süresi verildi. Videodan katılımcıların ayaklarının kalkış ve inişleri belirlendi. Daha sonra atlama yüksekliğini belirleyen denklem $\left(h=t^{2} x\right.$ 1,22625) kullanılarak sıçrama mesafeleri hesaplandı. En iyi sonuçlar değerlendirmeye alındı (Bosco ve ark., 1983).

Kuvvet Ölçümü (Back Squat): Genel ısınma protokolünden sonra hafif ağırlıklarla squat denemeleri yaptırıldı. Tüm katıımcıların ölçümleri aynı günde alındı. Katııımcıların 1 tekrar maksimumlarını (1RM) belirlemek için, yeni başlayanlara uygulanan ve sakatlanma olasılığı daha düşük olan 10RM yöntemi uygulandı (Brzycki, 1993). Bu yöntemin 1RM'yi daha doğru tespit ettiği bilinmektedir. Katııımcılar belirlenen tahmini başlangıç ağırlığı 10 tekrarda kaldırdı ve 10 tekrar yapamayıncaya kadar test devam etti (LeSuer ve ark., 1997). Formül yardımıyla çalışmaya katılan futbolcuların 1RM kuvvetleri hesaplandı. 


\section{Verilerin Analizi}

Verilerin istatistiksel analizinde SPSS.21 paket programı kullanılarak, futbolcuların tanımlayıcı analizleri ortalama ve standart sapma olarak hesaplanmıştır. Değişkenler arasındaki ilişkiler (Sürat, sıçrama performansları, mutlak ve relative kuvvet) Pearson korelasyon testi kullanılarak belirlenmiştir. Anlamlılık düzeyi $p<0.001$ olarak alınmıştır.

\section{Bulgular}

Tablo 1. Katıımcıların Tanımlayıcı Özellikleri

\begin{tabular}{|l|c|}
\hline U16 Ligi Futbolcularının Tanımlayıcı Özellikleri & Ortalama ve Standart Sapma $( \pm)$ \\
\hline Yaş $(\mathrm{y}$ ıl) & $15,78 \pm, 42$ \\
\hline Boy $(\mathrm{cm})$ & $172,43 \pm 7,89$ \\
\hline Vücut Ağırlığı $(\mathrm{kg})$ & $62,04 \pm 7,61$ \\
\hline
\end{tabular}

$\mathrm{cm}$ : santimetre, $\mathrm{kg}$ : kilogram

Çalışmaya katılan toplam 23 futbolcunun tanımlayıcı özellikleri olarak yaş ortalaması: $15,78 \pm, 42$ yıl, boy uzunluğu: $172,43 \pm 7,89 \mathrm{~cm}$, vücut kütlesi: $62,04 \pm 7,61$ $\mathrm{kg}$ olarak tespit edildi.

Tablo 2. Katılımcıların Sürat, Sıçrama ve Kuvvet Performans Özellikleri Ortalama Değerleri

\begin{tabular}{|l|c|}
\hline U16 Ligi Futbolcularının Performans Testleri & Ortalama ve Standart Sapma $( \pm)$ \\
\hline $5(\mathrm{~m})$ & $1,04 \pm 0,08$ \\
\hline $10(\mathrm{~m})$ & $1,65 \pm 0,15$ \\
\hline $30(\mathrm{~m})$ & $4,16 \pm 0,24$ \\
\hline $\mathrm{CMJ}(\mathrm{cm})$ & $38,9 \pm 4,49$ \\
\hline $\mathrm{SJ}(\mathrm{cm})$ & $31,8 \pm 4,80$ \\
\hline Mutlak Kuvvet $(1 \mathrm{RM})(\mathrm{kg})$ & $135,5 \pm 10,85$ \\
\hline Relative Kuvvet $(\mathrm{kg})$ & $2,20 \pm 0,16$ \\
\hline CMJ: Countermovement jump; SJ: Squat jump; 1RM: 1 tekrar maksimum; kg: kilogram; m: metre; cm: santimetre.
\end{tabular}

Katııımcıların Sürat, Sıçrama ve Kuvvet Performans Özellikleri Ortalama Değerleri ve standart sapmaları Tablo 2'de gösterilmiştir.

Tablo 3. Katııımcıların Sürat, Sıçrama ve Kuvvet Performans Özellikleri Arasında İlişki (Pearson Korelasyon)

\begin{tabular}{|l|c|c|c|c|c|}
\hline & \multicolumn{3}{|c|}{ Sürat (sn) } & \multicolumn{2}{c|}{ Siçrama (cm) } \\
\hline Mutlak Kuvvet (1RM) & $5 \mathrm{~m}$ & $10 \mathrm{~m}$ & $30 \mathrm{~m}$ & CMJ & SJ \\
\hline Relative Kuvvet & 0,59 & 0,19 & 0,37 & 0,20 & 0,30 \\
\hline
\end{tabular}

CMJ: Countermovement jump; SJ: Squat jump; 1RM: 1 tekrar maksimum; kg: kilogram; m: metre; cm: santimetre. ** $p<0.001$ 
Seyhan S. (2019). Süper Ligde Mücadele Eden Bir Kulübün U16 Ligi Futbolcularının Kuvvet, Sürat ve Dikey Sıçrama Performansları Arasındaki İlişkinin İncelenmesi. Gaziantep Üniversitesi Spor Bilimleri Dergisi, 4(1), 19-27.

Tablo 3 incelendiğinde katılımcılardan elde edilen mutlak kuvvet değerleri ile $(p=0,57)$ $5 \mathrm{~m}$ sürat testi sonucunda elde edilen ortalama değerler arasında güçlü bir ilişki olduğu görülmektedir ( $p<0.001$ ). Diğer ölçümler olan; $10 \mathrm{~m}, 30 \mathrm{~m}, \mathrm{CMJ}, \mathrm{SJ}$ değerleri ile mutlak ve relative kuvvet arasında bir ilişki olmadığı görüldü.

\section{Tartışma ve Sonuç}

Bu çalışma TFF Spor Toto Süper Lig Lefter Küçükandonyadis Sezonunda mücadele eden Akhisarspor Futbol Takımının U16 Ligi altyapı takımı futbolcuları ile $5 \mathrm{~m}, 10 \mathrm{~m}$ ve $30 \mathrm{~m}$ sürat performansları, dikey sıçrama performansları ve kuvvet performans değerleri arasındaki ilişkiyi belirlemek amacıyla 23 futbolcunun katılımı ile gerçekleşmiştir. Çalışmaya katılan toplam 23 futbolcunun yaş ortalaması: 15,78, \pm 42 yıl, boy uzunluğu: $172,43 \pm 7,89 \mathrm{~cm}$, vücut kütlesi: $62,04 \pm 7,61 \mathrm{~kg}$ olarak tespit edilmiştir.

Araştırmamızda en etkili sonuç olarak $0-5 \mathrm{~m}$ koşu performansı ile back squat 1 RM performansı $(p=0,57)$ arasında anlamlı bir ilişki olduğu görüldü $(p<0.001)$. Diğer bir yandan süratin diğer kompanentleri olan maksimum hıza ulaşma-yavaşlama $(10 \mathrm{~m}, 30 \mathrm{~m})$ ile back squat 1RM performansı arasında anlamlı bir ilişki olmadığı tespit edildi. Bu durumu çıkış anında yere uygulanan dikey kuvvet ve yerin tepki kuvveti ile back squat 1RM performansındaki uygulanan kuvvetin yönünün benzerliği ile açıklayabiliriz. Elde edilen sonuçlara göre $10 \mathrm{~m}$ ve $30 \mathrm{~m}$ performansında başlangıç evresinde vertical olan kuvvetin, ivmelenme ile birlikte horizantal kuvvete dönüştüğü ve vertical kuvvet ile üretilen back squat kuvvet performansının, $10 \mathrm{~m}$ ve $30 \mathrm{~m}$ koşu mesafeleriyle anlamlı ilişkili olmadığı görülmektedir.

Daha önce 30 erkek sporcu ile yapıımış olan bir çalışmada, sporcuların dikey olarak ürettikleri kuvvet değerleri ile $5 \mathrm{~m}$ başlangıç hızı arasında anlamlı bir ilişki olduğu görülmüştür (Sleivert ve Taingahue, 2004). Erişkin sporcular ve genç futbolcular arasında yapılmış olan iki ayrı çalışmada katıımcıların back squat performansı ile $5 \mathrm{~m}$ sürat performansları arasında anlamlı bir ilişki olduğu $(r=20.613)$ görülmüştür (Comfort ve ark., 2012; Comfort ve ark., 2014). Diğer bir çalışmada ise futbolcuların sıçrama ve sürat yeteneklerinin gelişmesi için maksimal kuvvet ile yarım squat çalışmalarının futbolcuların oyun performanslarını artıracağı gösterilmiştir (Wisloff ve ark., 2004). Futbolcular arasında yapılan başka bir çalışmada ise maksimal squat performansı oranındaki arış̧ı, kısa mesafeli sürat performansındaki 

19-27.

artı̧̧ da beraberinde getirdiği görülmüştür (Styles ve ark., 2016). Futbolcularda oyun süresince savunma ve hücum organizasyonları için kısa mesafe koşularında çıkış hızının önemli bir parametre olduğu ve oyun performansı ile sürat arasında yakın bir ilişki olduğu söylenebilir (Haugen, 2014). Öte yandan yapılan diğer bir çalışmada ise reaksiyon süresi ile $15 \mathrm{~m}$ hız performansı arasında anlamlı bir ilişki bulunmadığını tespit edilmiştir (Yıldız ve ark., 2018). Tüm bu sonuçlar ile sürat koşularının başlangıç evresinde büyük kas gruplarının kuvvet üretebilmek için hızlı bir şekilde kasılarak vücudu hareket ettirdikleri ve bu sayede sporcuların performanslarına olumlu katkı sağladıkları görülmektedir. Bu kas gruplarını uygun antrenmanlarla güçlendirmek çıkış anında sporcuların performanslarına olumlu yönde katkı sağlayacağı söylenebilir (Yun ve ark., 2016).

Bu nedenle alt ekstremite kas kuvvetini arttırmak, özellikle sıçrama ve sürat aktivitelerinin sık kullanıldığı sportif aktivite türleri açısından son derece önemlidir (Haff and Potteiger, 2001). Özel kas kuvvetini arttıran antrenman programları, kas kuvveti belirli bir seviyeye ulaştıktan sonra patlayıcı kas gücünün artışına olanak sağlamaktadır. Böylelikle kas gücünün artması ile kasların çok kısa sürelerde kasılması ve gevşemesi gerçekleşmektedir (Harman ve ark., 1990). Kuvvet ve kondisyon antrenörleri antrenman programlarına vertical güç üreten çalışmaları da mutlaka dahil etmeli, bu sayede de sporcuların vertical güç kazanımları ile birlikte daha iyi bir performans sergileyebilecekleri ifade edilmiştir (Loturko ve ark., 2016).

Sonuç olarak, antrenörlerin başarılı bir performans için sporculara vertical güç üretimini artıracak squat, deadlift gibi büyük kas gruplarına yönelik antrenmanları uygulaması, futbolcularının oyun sırasında kaslarının çok kısa sürede ve etkili şekilde kasılması ile çok daha başarılı başlangıç koşuları yapmalarına imkân sağlayabilir.

\section{Kaynaklar}

Ak, M. (2010). Türkiye Ve Azerbaycan Futbol Liglerinde Mücadele Eden U15 U16 U17 Takım Futbolcularının Aerobik Güç Performansının Karşılaştıııması, Selçuk Üniversitesi Sağlık Bilimleri Enstitüsü, Yüksek Lisans Tezi, Konya.

Balsalobre-Fernandez, C., Glaister, M. and Lockey, R.A. (2015). The Validity And Reliability of an İphone App for Measuring Vertical Jump Performance. J. Sports Sci., 33: 1574-1579. 
Bangsbo, J., Norregaard, L., Thorsoe, F. (1991). Activity Profile of Competition Soccer. Can J. Sport Sci., 110-116.

Bosco, C., Luhtanen, P. and Komi, P.V. (1983). A Simple Method For Measurement Of Mechanical Power In Jumping. European Journal Of Applied Physiology And Occupational Physiology, 50(2): 273-282.

Brzycki, M. (1993). Strength Testing - Predicting a One-Rep Max from Reps to Fatigue. Journal of Physical Education, Recreation and Dance, 64: 88-90.

Comfort, P., Bullock, N., and Pearson, S.J. (2012). A Comparison of Maximal Squat Strength and 5-, 10-, and 20-Meter Sürat Times, in Athletes and Recreationally Trained Men. J Strength Cond Res., 26: 937-940.

Comfort, P., Stewart, A., Bloom, L. and Clarkson, B. (2014). Relatıonshıps Between Strength, Sürat, and Jump Performance in Well-Traıned Youth Soccer Players. Journal of Strength and Conditioning Research, 28(1): 173-177.

Haff, G.G., and Potteiger, J.A.A. (2001). Brief Review: Explosive Exercises and Sports Performance. Strength and Conditioning Journal, 23(3): 13-20.

Harman, E.A., Rosenstein, M.T., Frykman, P.N. and Rosenstein, R.M. (1990). The Effects of Arms and Countermovement on Vertical Jumping, Med Sci Sports Exerc., 22(6): 825-33.

Haugen, T. (2014). The Role and Development of Sürating Speed in Soccer. University of Agder. Faculty of Health and Sport Science, Doctoral Thesis, 167.

LeSuer, D.A., McCormick, J.H., Mayhew, J.L., Wasserstein, R.L. and Arnold, M.D. (1997). The Accuracy of Prediction Equations for Estimating 1-RM Performance in the Bench Press, Squat and Deadlift. J. Strength Cond Res., 11(4): 211-213.

Loturco, I., Pereira, L.A. Kobal, R., Maldonado, T., Piazzi, A.F., Bottino, A., Kitamura, K., Cal Abad, C.C., Arruda, M. and Nakamura, F.Y. (2016). Improving Sürat Performance in Soccer: Effectiveness of Jump Squat and Olympic Push Press Exercises. PLOS ONE, 11(4): 1-12.

McBride, J.M., Blow, D., Kirby, T.J., Haines, T.L., Dayne, A.M., and Triplett, N.T. (2009). Relationship Between Maximal Squat Strength And Five, Ten, And Forty Yard Sürat Times. J Strength Cond Res., 23: 1633-1636. 
Mero A, Komi PV, Gregor RJ. (1992). Biomechanics of Sürat Running. A review. Sports Med., 13: 376-392.

Sleivert, G. and Taingahue, M. (2004). The Relationship Between Maximal JumpSquat Power and Sürat Acceleration in Athletes. Eur J Appl Physiol, 91(1): 46-52.

Styles, W.J., Matthews, M.J and Comfort, P. (2016). Effects of Strength Training on Squat and Sürat Performance in Soccer Players. J Strength Cond Res,. 30(6): 1534-1539.

Turna, B. and Kılınç F. (2016).Examining the Relation Between the Performance Levels of the Footballers and the Data Obtained With the Routine "Combined Performance Analyses". 6(11); 657-668.

Turna, B. and Kılınç F. (2018). Comparison of some Biomotoric Properties and Anthropometric Measurements of Male Basketball and Football Players. Journal of Education and Training Studies. 6(5);118-122.

Vigne, G., Gaudino, C., Rogowski, I., Alloatti, G. and Hautier, C. (2010). Activity Profile in Elite Italian Soccer Team. Int J. Sports Med., 31: 304-310.

Willigenburg, N.W, McNally, M.P, Hewett, T.E. (2015). Quadriceps and Hamstrings Strength in Athletes in: Kaeding, C.C., Brochers, J.R., Editors. Hamstrings and Quadriceps Injuries in Athletes: A Clinical Guide, New York, Springer Science Business Media, 79-85.

Wisloff, U., Castagna, C., Helgerud, J., Jones, R. and Hoff, J. (2004). Strongcorrelation of Maximal Squat Strength with Sürat Performance and Vertical Jump Height in Elite Soccer Players. Br J Sports Med., 38: 285-288.

Withers, R.T., (1982). Match Analyses of Australian Professional Soccer Players. Journal of Human Movement Studies, 8: 159-176.

Yııdız, S., Ateş, O., Gelen, E., Çırak, E., Bakıcı, D., Sert, V. and Kayıhan, G. (2018). The Relationship Between Start Speed, Acceleration and Speed Performances in Soccer. Universal Journal of Educational Research, 6(8): 1697-1700.

Yun, S.J., Weon, J.H., Jung, S., Kim, M.H., Kim, Y. and Kwon, O.Y. (2016). Correlation Between Toe Flexor Strength and Ankle Dorsiflexion ROM During The Countermovement Jump. J Phys Ther Sci. 28(8): 2241-2244. 